\title{
Improving English Language Speaking Skills Using "Absyak" On-Line Learning Model for Second Semester in Higher Education
}

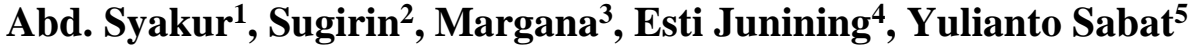 \\ ${ }^{1 \& 5}$ Postgraduate Program of English Education, STKIP PGRI Sidoarjo, Indonesia \\ ${ }^{2 \& 3}$ Postgraduate Program of English Education, Universitas Negeri Yogyakarta, Indonesia \\ ${ }^{4}$ Doctoral Environmental Assessment and Development Program, UniversitasBrawijaya, Indonesia \\ syakurabdmpd@gmail.com
}

\section{Abstract}

This study aims to improve students' speaking skills. The research sample consisted of 30 students (20 female students and 8 male students) all of whom were studying English, the majority of the sample were second semester students, the form of this study was to analyze (1) teaching and learning plans to speak through the task of information gaps that exist in "Absyak" on-line learning media websites, (2) the implementation of teaching speaking through structured tasks and information gaps with "absyak" online learning media websites, (3) teaching teaching evaluation systems through the task gap "absyak" information media websitebased online learning, (4) improvement of student speaking using the information gap task on "absyak" website-based on-line learning. This is a classroom action research that takes place in 2 cycles. The subjects of the study were the second semester students of Surabaya Pharmacy Academy, Regular Class A consisting of 30 students in the academic year 2019/2020. Data collected by tests, observation notes and documentation. Data were analyzed descriptively qualitatively. The results showed that learning that was designed using the information gap technique with "absyak". Website-based online learning with cycle procedures. Cycle I results are still not optimal, then continue to the second cycle. In cycle II the results are maximum. Student activities increase every cycle II for learning, student activity, performance indicators, learning processes, completeness scores increase, decrease the number of unfinished and success indicators. Based on the results of research 11 which has been conducted 11 with 1 application of information gap techniques and "absyak" on-line learning website in learning Speaking in the second semester students of the Surabaya pharmacy academy that there is a significant increase in speaking skills from the results of learning achievements of cycle I and cycle II. This means that the students' speaking skills from the stages are increasingly increasing and succeeding well.
Keywords

speaking skill online media; website based information gaps

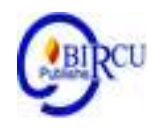

\section{Introduction}

Language is a medium of communication between humans. Language is needed by humans because human language can find their needs by communicating. As members of the community who are active in everyday life, people are very dependent on the use of 
language. In other words, where activities occur, there is also a language activity (Chaer in Syahrin 2018).

Speaking is a language skill that has to be mastered by students in learning a language because the objective of learning a language is communication. Richards (2008:19) states that in speaking we tend to be getting something done, exploring ideas, working out some aspects of the world, or simply being together. Speaking English well also helps students access up to update information in fields including science, technology and health. The students have to master all components of speaking skill (Sari,2019). This skill is an important indicator for the success of someone to be able to speak English correctly and fluently especially for the younger generation in general and students in particular in learning English(Budiarta and Krismayani, 2014, Antony et al., 2015). This opinion clearly indicates that speaking skills imply someone knows a language (Moussu and Llurda, 2008). By mastering good speaking skills, students can communicate their ideas, both in class and with foreign speakers, and also maintain good relations with others. These skills are closely related to pronunciation, grammar, vocabulary, discourse, listening skills, and so on(Páez and Rinaldi, 2006)

The importance of having English speaking skills as a communication tool and thinking tool is also seen in the Speaking English course. In general, students still find it difficult to convey ideas, thoughts, questions and so on using English correctly and smoothly(Moussu and Llurda, 2008). This often happens due to many factors such as insecurity, fear, shame, and sometimes fear of being mistaken for grammar and vocab when expressing his ideas.

Students in learning English are required to master three aspects of language, namely pronunciation, grammar and vocabulary. These three aspects are realized in four language skills, namely listening, speaking, reading and writing skills(Moussu and Llurda, 2008). Facts in the field show that student achievement in the Speaking Skills subject has not yet reached the success standard (KKM score of 75). The standard has not been reached due to several factors such as; lack of mastery of vocabulary, never tried to communicate using English in class and ashamed to communicate using English. Besides learning also has not been designed in a visionary sustainable or known as (ESD) educational Suntan Able Development(Wats and Wats, 2009).

In accordance with the principle of the information gap task on "absyak" on-line learning based on websites where students have not been able to play an active role in the learning process. Without realizing it, various realities are often inflicted on students for various reasons. However, if we look closely, are there really other factors that cause low student learning outcomes in English, for example lecturer factors are already based (Students Centered) which include: (1) Is the English learning process so far good and easies?, (2) Is lecturers are already using online media which in this era is being promoted and varied techniques for achieving learning objectives?. The use of language skills, lecturers should be more optimal in the process of implementing Speaking learning for second semester students by using website-based on-line media or learning techniques (Songsiri, 2007, Moussu and Llurda, 2008). Lecturers are expected to be able to convince students to speak in English.

On the other hand evaluation criteria in speaking learning are still not used optimally by lecturers. Evaluating speaking skills is considered more difficult than other language skills, because it includes several components that must be mastered by students such as; vocabulary, pronunciation, fluency and grammar so there is a need for more detailed speech evaluation criteria. The learning process can be developed by providing a variety of media such as animation, audio visual or techniques such as information gap techniques with website-based "absyak" learning. 
Along with what is explained in the background of the problem, the purpose of this study is to analyze: 1) Speaking learning planning design using information gap and "absyak" on-line learning based on the website to improve speaking skills in the second semester students of Regular A Pharmacy Academy Surabaya. 2) the process of implementing Speaking learning by using information gaps and "absyak" on-line learning based on websites to improve speaking skills in semester II Regular students at the Surabaya Pharmacy Academy. 3) Speaking learning outcomes by using information gap and "absyak" on-line learning based on websites to improve speaking skills in semester II Regular students of the Surabaya Pharmacy Academy. And 4) evaluation of Speaking learning by using information gap and "absyak" on-line learning based on websites to improve speaking skills in Regular semester II students of the Surabaya Pharmacy Academy.

\subsection{The Concept of Speaking Learning}

The ability to speak is the ability to communicate verbally with others. This ability provides an overview of the ability to compile various vocabulary that has been mastered into a series of structured talks (Hasibuan, 2019).

Speaking is a process of thinking and reasoning so that someone's conversation can be accepted and understood well by others or listeners. Speaking is closely related to listening skills. Both are a unified unity.

"Children in learning their first language appear to do a lot of listening before they speak, and that their listening is accompanied by physical responses (reaching, grabbing, moving, looking and so forth)".

Based on the opinion of language experts related to Speaking, it can be concluded that Speaking learning is an activity of conveying a message or information to others in oral form (Páez and Rinaldi, 2006). Learners will be more successful if they often do the exercises in pronunciation before they use the language.

\subsection{The Concept of Learning Information Gap}

Information gap technique is a combination of which (face) technique, pretending to forget (loss of memory), and sharing information (shared information)(Mayfield, 2011). This activity is one form of many communicative activities.

\subsection{The Concept of "Absyak" Website-Based Online Learning}

"Absyak" which is an on-line learning model specifically designed by researchers in the form of soft ware that has been tested for validation refers to the SN-DIKTI about learning initiator media and as a forum for Distance Learning Processes (PJJ) for tertiary institutions.

On the other hand Web-based learning that is popular with a million Web-Based Educations (WBE) or sometimes called e-learning (electronic learning) can be defined as a web technology application in the world of learning for an educational process. it can be said simply that all learning is done by utilizing internet technology and as long as the learning process is felt to occur by those who follow it, then the activity can be referred to as webbased learning.

Internet technology makes it easy for anyone to get any information from anywhere and anytime easily and quickly. Information available in various data centers on various computers in the world. As long as these computers are connected to each other on the internet, we can access them from anywhere. This is one of the advantages of learning via the internet. 
Realizing web-based learning is not just putting learning material on the web to then be accessed through a web computer, but it is also used only as a alternative media replacement paper in other words environmentally friendly learning to store various documentation and information. The web is used to get the superior side that was revealed earlier. Advantages that are not owned by media or other media.

According to(Lindsey et al., 2003)opinion about the development of e-learning is there are three possibilities in the development of internet-based learning systems, namely web courses, web centric courses, and web enhanced courses. Web courses are used for educational purposes, where students and lecturers are completely separate and there is no need for face-to-face meetings. All teaching materials, discussions, consultations, assignments, exercises, exams, and other learning activities are fully delivered via the internet.Web centric course is the use of the internet that combines distance learning and face to face. Part of the material is delivered via the internet, and partly through face-to-face, the functions are complementary.

Web enhanced course is the use of the internet to support the improvement of the quality of learning done in class. The function of the internet is to provide enrichment and communication between students and lecturers, fellow students, group members, or students with other sources.

\subsection{Learning Design}

This study uses the ASSURE design model because this model does not explicitly mention the learning strategy. This model is a reference for educators in learning students in planned learning and arranged systematically by integrating any technology and media-based so that learning becomes more effective and meaningful for students. Learning by using the ASSURE Model has several stages as follows:

1. Analyze Learner

2. State Standards and Objectives (Determining Standards and Objectives) Learning objectives based on $\mathrm{ABCD}$, the $\mathrm{ABCD}$ standard formulation was described as follows: $\mathrm{A}=$ audience, $\mathrm{B}=$ behavior, $\mathrm{C}=$ conditions and $\mathrm{D}=$ degree.

3. Select Strategies, Technology, Media and Materials (Choosing, Strategy, Technology, Media and Teaching Materials).

4. Utilize Technology, Media and Materials (Using Technology, Media and Teaching Materials)

5. Require Learner Participation (Developing Student Participation)

6. Evaluate and Revise (Evaluate and Revise).

\subsection{Learning Evaluation}

"The test is a form of evaluation tool to measure how far the teaching objectives have been reached, so it means an evaluation of learning outcomes. A good test must meet certain requirements; 1) must be efficient (parsimony) 2) must be standardized (standardize) 3) have norms 4) objective 5) valid (valid) 6) reliable (reliable), ". To get a good test, the test must be analyzed so that it meets these requirements. 


\section{Research Method}

Classroom Action Research on Improving English Language Speaking Skills using "absyak" This on-line learning model for second semester in higher education is carried out in two cycles, each cycle consisting of 2 meetings. The design of this study uses the Arikunto model which consists of 4 components: planning, implementation, observation, and reflection

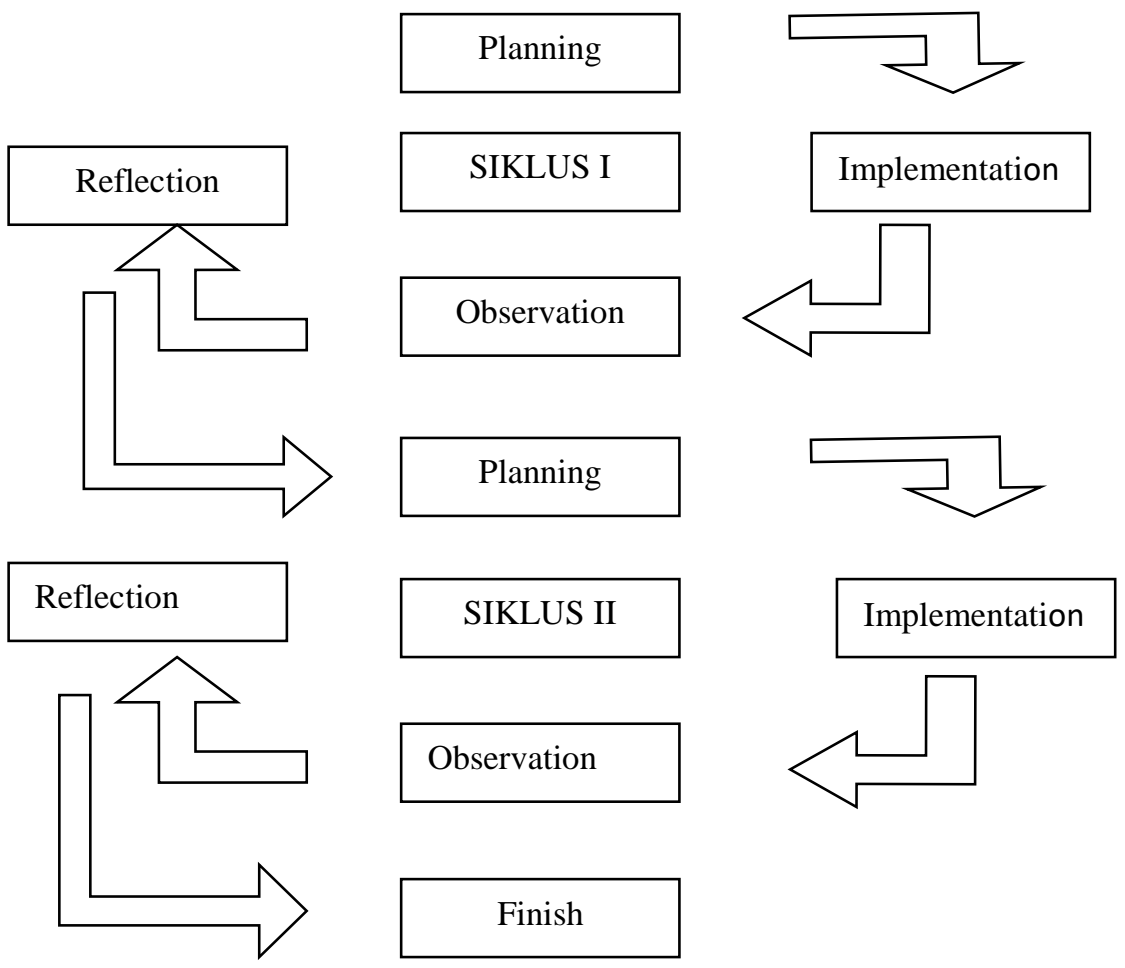

(Arikunto and Jabar, 2004)

Figure 1. Classroom Action Research Model

\subsection{Stage 1 Planning}

Planning at this stage the researcher plans the preparation of learning activities such as: preparing research classes, Semester Program Plans (RPS) and lesson plans, research instruments for lecturers and students, learning resources in the form of information gap supporting worksheets and website-based "absyak" learning on-line learning which will be used in the form of pictorials, animations and multimedia devices such as computers, slides, and LCDs, and pre-test - cycle I tests

\subsection{Stage 2 Implementation}

This research was conducted in two cycles, each cycle consisting of two times face to face. The steps of activities that must be carried out by the lecturer include explaining the Speaking learning material as well as clear instructions about the steps of learning activities which are divided into three stages, namely pre-activity, during activity (while-activity), and post-activity ( post-activity) through the LCD screen about the learning content available on the website including: (1) In the pre-activity stage, the lecturer is motivated by a question and answer session about the material at the previous meeting and divides students into pair groups, (2 ) The lecturer asks one person from each group to come forward and the lecturer 
gives each student a picture that is listed on the website and is free to choose whether it is video, animation about drugs that must be provided to the family and then asks them to understand the purpose of the picture the. (3) During the phase of the activity (while-activity), the lecturer asks the group representative to convey the contents of the picture to their colleagues, and they are instructed to ask questions about the family tree of medicine they have in their respective homes. (4) Students exchange information about the pedigree of medicines from their families in their homes. (5) Next in the post-activity stage, the lecturers and students conclude learning on the meeting material and students respond to the stimulus given during the learning. (6) The activity ends with the provision of online-based tests where direct results can be viewed on each website.

\subsection{Stage 3 Observation}

Observations As the research progresses, collaborators as the second observer carry out observations and evaluations using lecturer observation sheets

\subsection{Stage 4 Reflection}

Researchers At the reflection stage and collaborators together collect data and information in the form of findings on the level of effectiveness of student learning towards the learning process, as well as the obstacles experienced during the learning process in cycle I need to be corrected in cycle 1 II.

\section{Finding and Discussion}

\subsection{Cycle I}

Implementation of the observed learning as shown in Table 1 and images 2 . The results of observations of the implementation of learning conducted by lecturers are still not optimal with a percentage of $69 \%$ carried out by lecturers. Implementation of learning observed from student activities in the learning process percentage of the number of active students $27 \%$ have not reached the indicator of success. The implementation of taking the final value of the cycle that serves to determine student learning achievement in the first cycle apparently has not been carried out according to the procedure, in this case the validity of the assessment results has not been achieved, because the test of speaking skills is subjective. So ideally, testing is carried out with an inter-rater system or two examiners Indicators that determine success for learning planning is a score of 4, namely preparation of learning materials and materials, preparation of learning media and preparation of evaluations.

Table 1. Results of the implementation of learning cycle I and cycle II

\begin{tabular}{lcc}
\hline Characteristics & Cycle I (\%) & Cycle II (\%) \\
\hline Learning & $69 \%$ & $100 \%$ \\
Active Student & $27 \%$ & $100 \%$ \\
Achievements & $89 \%$ & $96 \%$ \\
Learning process & $70 \%$ & $100 \%$ \\
Complete score & $25 \%$ & $86 \%$ \\
Not complete yet & $75 \%$ & $12 \%$ \\
Success & $45 \%$ & $75 \%$ \\
\hline
\end{tabular}


Indicators of success for learning planning have not been achieved because the total score is still below 96 (89). Implementation of the observed learning as a whole has been carried out, this is evidenced by the assessment indicators that get a "yes" checklist on all components observed. This indicator shows that the lecturer has carried out all steps of learning according to the specified procedures. Implementation of learning observed from student activities in the learning process percentage of the number of active students $70 \%$ have not yet reached the indicator of success. Then the appraisal system at the instrument preparation stage has gone according to procedure. However, the scores achieved by students did not match the expectations set in the indicators of success. The results obtained in the first cycle, namely the percentage of the number of students who completed was $25 \%$. Student achievement has not yet reached the $75 \%$ success indicator so it needs to be improved in the next cycle.

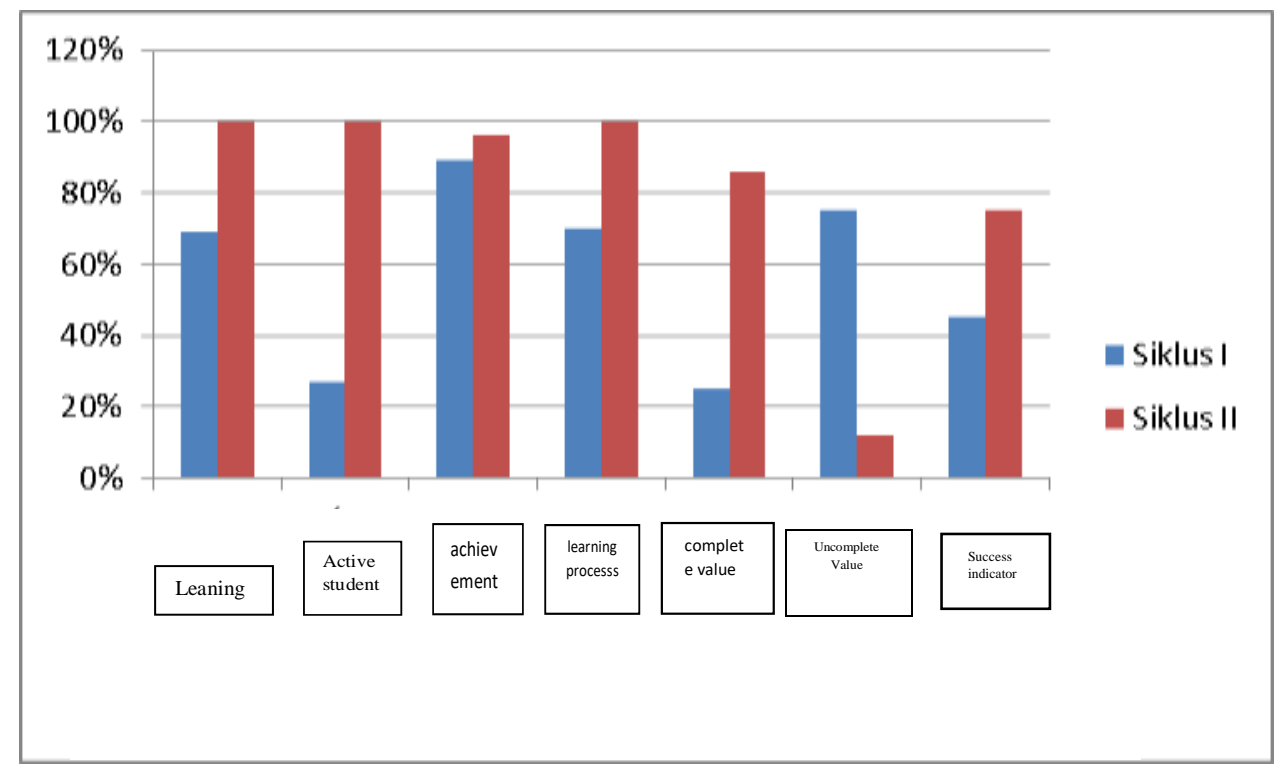

Figure 2. Results of the implementation of learning cycle I and cycle II

\subsection{Cycle II}

The value of learning planning for each indicator gets a score of 4 . So, the indicator of success for learning planning has been achieved because the total score is 96 (Table 1 and Figure 2). The overall learning management implementation of learning has been carried out, this is evidenced by the assessment indicators that get a "yes" checklist on all components observed or $100 \%$ implemented. Observer observations obtained that there are 30 active students that is $100 \%$ of the number of students observed. Student activeness increased from $70 \%$ to $100 \%$ even though some students did not meet 3 indicators out of 4 expected activeness indicators. This is still in the good category, so the study was stopped in the second cycle. The evaluation of learning for the test has been tested for validity and found that the test is valid because it can show the true abilities of students. According to face validity, the test is valid and meets the elements of reliability, practicality, and authenticity. Then the percentage of students who complete is $86 \%$. Student learning achievement has reached the specified success indicator of $75 \%$ so that the cycle action is stopped. 


\subsection{Reflection}

The quality of RPS and RPP compiled by lecturers, based on the results of calculations on learning planning using information gap techniques and website-based "absyak" on-line learning, shows that learning planning from cycle I and II has increased scores. In cycle I, the total score of the quality of RPS and RPP given by the assessor is 78. If it is associated with the indicators of success set for learning planning, the total score is above 96 and no indicator has a score below 3, meaning that in cycle I it is said to have not been successful. Then in cycle II the RPS and RPP quality scores given by the appraiser are 96 and there are no indicators with values below 3 meaning that the RPS and RPP have met the indicators of success. Good learning planning contributes greatly to the success of students to achieve learning goals in accordance with KKM planned. At this planning stage learning activities that direct students to the full activity can be checked for compatibility with the concept of constructivism understood by the lecturer, according to(Henard and Roseveare, 2012) that the constructivist approach to learning is based on a combination of cognitive psychology and social psychology(O'Neill and Palmer, 2004). With constructivism theory students can think to solve problems, find ideas and make decisions(Songsiri, 2007). Putting together a good plan in the sense of being relevant and consistent with the concept of constructivism is not easy. Thus the researcher involves other people, namely experienced senior lecturers, to see, study, and assess the planned learning plan. The assessment of these peers provides feedback to improve planning. This has led to an increase in learning planning assessments from cycles I and II.

The implementation of learning using information gap techniques and website-based "absyak" on-line learning that is carried out during the learning process progresses from cycle I and II. In the first cycle the percentage of the score of learning implementation indicators was $69 \%$, this means the implementation of good quality learning. In cycle II the percentage of the score of learning implementation indicators is $100 \%$. This means that the implementation of critical learning is very good. Based on the observational data and a description of the implementation of learning carried out with directional steps and appropriate time management at each stage of learning activities it can be said that learning using information gap techniques and "absyak" on-line learning on a website-based basis can improve learning activities and skills outcomes speak English in a standard of competence the ability to give news that attracts attention, comment on information received and ask for information and opinions. Furthermore, based on the findings, student activities during the learning process using information gap techniques and website-based "absyak" on-line learning, the results obtained in the first cycle the percentage of students who are active in learning as much as a percentage of $27 \%$, for the second cycle increases with the number students are classified as active as many as 30 people with a percentage of $100 \%$. Based on the results obtained it can be seen that the percentage of students who are classified as active each cycle has increased. An increase in the number of students classified as active because students begin to be motivated and confident to be active in the learning process, and the formation of group work and pairwork is very influential on student activity(Wats and Wats, 2009, Budiarta and Krismayani, 2014). In principle, the urgency of small groups and pair groups is equal because they interact more than one student. This means that students can work together and solve problems quickly, then weak students are helped by other colleagues and make it easier for lecturers to control students. 
The assessment system is carried out according to procedure, the test questions used to measure learning achievement have been prepared by going through the stages of composing the questions starting from the preparation of the grid, compiling the questions, and testing the questions. The number of test items in cycle I and cycle II is 1 valid question in the form of oral questions, with clear instructions and can show the real abilities of students. According to face validity, the test is valid because it fulfills several criteria, such as: wellstructured, can be done clearly, clearly and does not complicate students, have clear instructions, refer to the curriculum, and provide challenges of difficulty. Based on the value of the reliability of the test results, the test results are reliable, because, students are tested with inter rater reliability (reliability between testers - two testers). In terms of practicality, the test is practical because it saves time, as evidenced by the ability to test 30 students in just 60 minutes. In terms of authenticity, the test is authentic because it links students' abilities to daily life and interactional in language skills. In the aspect of scoring, the test has a clear scoring, because it is able to show their abilities specifically. In general, the results of student learning assessments always increase from each cycle.

Student achievement has increased from cycles I and II. This increase can be seen from the percentage of the number of students who have finished learning, students who have finished studying are students who have scores equal to or more than the Minimum Mastery Criteria (KKM) set 75 in the first cycle the percentage of the number of students who have completed 50\% also has not yet reached the indicator of success, and in cycle II the percentage of students who completed $86 \%$ meant that more than the indicators had been set. Based on the results of observations in the second cycle, the percentage of students who complete is $86 \%$. This means that it has reached the established indicator. An increase in learning achievement from the Idan II cycle indicates that the learning process using information and "absyak" website-based on-line learning can stimulate students to learn. Students are motivated because of their interest in the use of information gap techniques and "absyak" on-line learning based on websites that are supported by media images as well as interview and role play activities both in pair group work and small group work during the learning process are presented. The use of information gap and "absyak" on-line learning based on websites in learning makes students motivated to learn, able to guide students to learn independently and can draw conclusions on the subject being taught. The application of information gap techniques and website-based "absyak" on-line learning that is used can encourage students to develop activities and creativity in learning. Thus able to actively encourage students to develop and improve their skills and potential. This has implications for the achievement of good learning achievement in students. In addition to increasing student activity in learning, learning English speaking skills using information gap techniques and website-based "absyak" on-line learning also triggers mastery of the concept of student learning achievement.

\section{Conclusion}

Based on the results of research that has been carried out with the application of information gap techniques and "absyak" on-line learning on a website-based basis in Speaking learning in the second semester students of the Surabaya pharmacy academy that there is a significant increase in speaking skills from the results of the learning achievements of the first cycle and second cycle and declared successful by using information gap techniques and "absyak" on-line learning based on the website also triggers the mastery of the concept of achieving students in learning. 


\section{References}

Antony, J., W. K. Balzer, M. H. Brodke, and E. T. Kizhakethalackal. 2015. Lean higher education: successes, challenges, and realizing potential. International Journal of Quality \& Reliability Management.

Arikunto, S. and C. S. A. Jabar. 2004. Evaluasi program pendidikan pedoman teoritis praktis bagi praktisi Pendidikan. Jakarta: Bumi Aksara.

Budiarta, I. K. and N. W. Krismayani. 2014. Improving speaking skill and developing character of the students through collaboration of think-pair-share and the concept of tri kaya parisudha. Jurnal Santiaji Pendidikan (JSP) 4(2):73-80.

Hasibuan, S. (2019). Development of Child Worksheets Based on the Story as Subtheme "My Body" to Improve Students' Speaking Abilities at Al-Ikhlas Early Childhood Education and Development (ECED) Medan Amplas. Budapest International Research in Linguistics and Education Sciences (BirLE), P.539-546.

Henard, F. and D. Roseveare. 2012. Fostering quality teaching in higher education: Policies and practices. An IMHE Guide for Higher Education Institutions:7-11.

Lindsey, K. A., F. R. Manis, and C. E. Bailey. 2003. Prediction of first-grade reading in Spanish-speaking English-language learners. Journal of educational psychology 95(3):482.

Mayfield, M. 2011. Creating training and development programs: using the ADDIE method. Development and Learning in Organizations: An International Journal 25(3):19-22.

Moussu, L. and E. Llurda. 2008. Non-native English-speaking English language teachers: History and research. Language teaching 41(3):315-348.

O’Neill, M. A. and A. Palmer. 2004. Importance-performance analysis: a useful tool for directing continuous quality improvement in higher education. Quality assurance in education.

Páez, M. and C. Rinaldi. 2006. Predicting English word reading skills for Spanish-speaking students in first grade. Topics in Language Disorders 26(4):338.

Sari, A. (2019). Improving Students' English Speaking Skill Through the Implementation of Talking Stick Method to the Fifth Grade Students of State Primary School 028226 Binjai. Budapest International Research in Linguistics and Education Sciences (BirLE), P. 507-513.

Songsiri, M. 2007. An action research study of promoting students' confidence in speaking English. Victoria University.

Syahrin, A. (2018). Culture Repertoire in Expressive Written Language : Study of Hypothesis of Edward Sapir and Benyamin Lee Whorf. Budapest International Research in Linguistics and Education Sciences (BirLE).P 23-28.

Wats, M. and R. K. Wats. 2009. Developing Soft Skills in Students. International Journal of Learning 15(12). 